\title{
Knowledge Management Applied to Electronic Public Procurement
}

\author{
Helena Lindskog ${ }^{1}$ and Eunika Mercier-Laurent ${ }^{2}$ \\ ${ }^{1}$ Department of Management and Engineering, Linköping University, Sweden \\ Helena. Iindskog@liu.se \\ ${ }^{2}$ MODEME, Centre Magellan, Jean Moulin University, Lyon3, France \\ e.mercier-laurent@univ-lyon3.fr
}

\begin{abstract}
Public procurement is a knowledge-based process. It involves, amongst others the knowledge of needs and trends, knowledge of concerned products or services, on their evolution in time and knowledge about actors able to offer them. The knowledge of political and legal context should be also considered as well as the environmental and social impact. Electronic procurement aims in reducing the amount of paper, but also in quicker and more knowledgeable processing of proposals and decision taking. We consider procurement activity as a part of a global organizational knowledge flow. This work goal is to analyze the whole process, identify the elements of knowledge necessary for successful purchase processing, to study the contribution of AI approaches and techniques to support the above elements. It is also to position e-procurement in the organizational knowledge flow.
\end{abstract}

Keywords: Procurement, Public Procurement, e-procurement, Knowledge Management.

\section{$1 \quad$ Public Procurement}

Purchasing is one of the most important activities for any kind of organization. Axelsson and Håkansson [3] define three different roles for purchasing:

- The rationalization role - to buy at very competitive prices which will put pressure on supplier efficiency.

- The developing role - to monitor the technical development (product and process) in different supplier segments and to encourage the suppliers to undertake technical development projects.

- The structuring role - to develop and maintain a supplier structure with a high potential for both development and efficiency.

While purchasing is in many ways similar for both public and private sectors, public procurement is in almost all situations and countries regulated by a specific legislation, which is stricter than the one that regulates the private sector's purchasing activities. For example, in public procurement environment the Request for Proposal (RfP) 
after it has been published cannot be changed, there is a possibility to appeal for suppliers if they consider themselves of being unfairly treated in the tendering process and must be taken into consideration not only economical but also political goals such as environmental and societal. The closest similarity between public procurement and private purchasing is probably in the case of acquisitions of large investments, often called project purchasing [1], [4], [15] and [30].

Public procurement activities by European Union member states are based on the principles from the Treaty of Rome (1957) aiming for establishing the free market within the EU is the base for public procurement and follows five fundamental principles:

Non-discrimination - all discrimination based on nationality or by giving preferences to local companies is prohibited.

Equal treatment - all suppliers involved in a procurement procedure must be treated equally.

Transparency - the procurement process must be characterized by predictability and openness.

Proportionality - the qualification requirements must have a natural relation to the supplies, services or works that are being procured.

Mutual recognition - the documents and certificates issued by the appropriate authority in a member state must be accepted in the other member states [38].

Public procurement has great importance for the economy of any country, and for the European Union it accounts "for almost one-third of government expenditure. In 2009, it amounted to $19.4 \%$ of GDP - or 2.2 trillion EURO - of all the income generated in the EU” [41].

A considerable part of all purchasing activities on any national market is due to public procurement and corresponds to around 19.4\% of the European Union's GDP: "at the local/regional level public procurement can easily reach the double of that in terms of percentage of public expenditure. For the example, a study of public procurement across Baltic city metropolises(3) shows that public procurement accounts for $40 \%$ of the city budget in Helsinki and 30\% in Stockholm" - CORDIS Community Research and development of Information Service [40].

\section{Electronic Public Procurement}

Electronic procurement has over a number of years gained recognition in both private and public sectors. More and more parts of the procurement process are done electronically, even to carry out the whole tendering process electronically. Leukel and Maniatopoulos [20] define "in a public sector context, e-Procurement as a collective term for a range of different technologies that can be used to automate the internal and external processes associated with the sourcing and ordering process of goods and services". 
In Sweden, in December 2005, Verva ${ }^{1}$ published a report for a national action plan of procurement stressing that both buyers and suppliers would benefit from electronic methods for procurement and that the whole procurement process from planning to billing should and could be done electronically. Sveriges Kommuner och Landsting (The Swedish Association of Local Authorities and Regions) is heading another important Swedish project - SFTI (Single Face to Industry) that aims to standardise the communication between public and private organisations. It has received international attention.

The Swedish research project KNUT (Electronic Public Procurement of Telecommunications Services), sponsored by the Swedish government agency Vinnova ${ }^{2}$, was an attempt to develop electronically the missing parts of the whole public procurement process by in a systematic and structured way collect and analyze needs and incorporate the legacy system. This approach is of special importance in the public procurement environment, since after the publishing of the RfP, no changes can take place. When the pre-formal phases of the public procurement process are carried out electronically, the results can be directly transferred to the electronically produced RfP. One of the objectives of the project was to increase the number of SMEs participating in the public procurements [22].

The first parts of the procurement process to be standardized and electronically applied were ordering and billing. This is due to the relatively low complexity and limited number of solutions for these parts of the procurement process.

According to IDABC (Interoperable Delivery of European e-Government Services to public Administrations, Businesses and Citizens) [37] e-Procurement can benefit:

Public Administrations: e-Procurement should minimize the time and effort expended by administrations and contracting authorities for organizing public procurement competitions.

Businesses: It will also benefit enterprises keen to trade across borders, by giving them improved and easier access to public procurement opportunities across Europe.

Citizens: Making procurement procedures available to a larger audience of suppliers enables the public sector to purchase goods and services at more economically advantageous prices. Citizens will have reassurance that their administrations are spending money in a more cost-effective manner.

The implications of electronic public procurement and the objectives for using electronic public procurement are many and can be summarized as:

\footnotetext{
${ }^{1}$ Verva was one of the Swedish Government's central advisory agencies. Today, public coordination of framework contracts concerning products and services for the entire public sector in the fields of information and communications is carried out by Kammarkollegiet.

${ }^{2}$ Vinnova - (Swedish Governmental Agency for Innovation Systems) is a State authority that aims to promote growth and prosperity throughout Sweden. The particular area of responsibility comprises innovations linked to research and development. The tasks are to fund needs-driven research required by a competitive business and industrial sector and a flourishing society, and to strengthen the networks that are necessary parts of this work.
} 
- To reduce public sector spending. In the context of public procurement, cost reduction can be divided into three types:

- Overall

- The reduction can be achieved by purchasing goods and/or services that correspond to the authorities' specific needs (not too much, which could unnecessarily increase costs, or too little, which risks not meeting the authority's current and future needs) or by changing internal processes using new technologies or other innovative approaches. One example can be increased usage of information communication technology, which may signify increased cost of purchasing in order to reduce the overall cost.

- For specific service and/or goods

- Standardized procedures and descriptions of products reduce the cost for the preparation of tenders. Electronic procurement makes it possible for more suppliers to be aware of and easier bid for government contract and/or through economy of scale in case of framework contract

- Of the procurement process

- By using models, standardized procedures for every phase of the public procurement process and concentrating on analysis of needs specific for the authority, thus, to reduce the amount of time and the number of staff involved in the process.

- To increase the service level. Usage of the same standardized procedures and description of goods and services makes it easier for the suppliers to know how to bid for the government contracts. Usage of a model for the analysis of needs and standardized Request for Proposal reduces the number of misunderstandings.

- To increase the number of SMEs

- To reduce the dependency on consultants. Electronic procurement gives the possibility for authorities to use the aggregate knowledge from earlier procurements in the same area and of similar type of authorities, thus, to reduce the need for external workforces, especially for less qualified type of information.

- To increase competition. Standardized procedures, models for structuring needs and requirements, and easier access to information about forthcoming public procurements and to electronic RfP facilitate the possibility for a bigger number of companies and from more EU countries to participate in public procurements

- To rationalize and increase efficiency. This is especially valid in case of carrying out the whole procurement process electronically. Even a partially electronic process such as for example e-Invoicing can give substantial gains.

- To increase the possibility to aggregate knowledge. Electronic procurement makes it much easier to collect statistics over existing procurements and analyze criteria, requirements, contracts and/or outcomes in order to attune new specifications and to avoid mistakes.

- To increase the possibility to put pressure towards more standardization. If the statistics based on a big number of procurements show similar difficulties in achieving satisfactory results depending on the lack of standards for specific functionality, there is pressure on standardization organizations to develop and prioritize standards that are in demand by the users. 
- To empower each agency. Easy access to information about how to make an analysis of needs using appropriate models, specify requirements automatically based on analysis of needs and develop a Request for Proposal corresponding to an authority's needs gives the possibility to carry out the entire procurement process by the agency itself.

The most important conclusion is that carrying out the whole procurement process electronically can lead to considerable gains of rationalization and efficiency. The upgradeable and scalable model enables analysis of needs, collection of information about the legacy of currently valid contracts and a direct transformation of these results into the RfP. Thus, the whole process can be carried out electronically.

\section{$3 \quad$ Analysis of a Public Agency Purchasing Activity}

The purchasing activity of a public agency is presented in Figure 1.

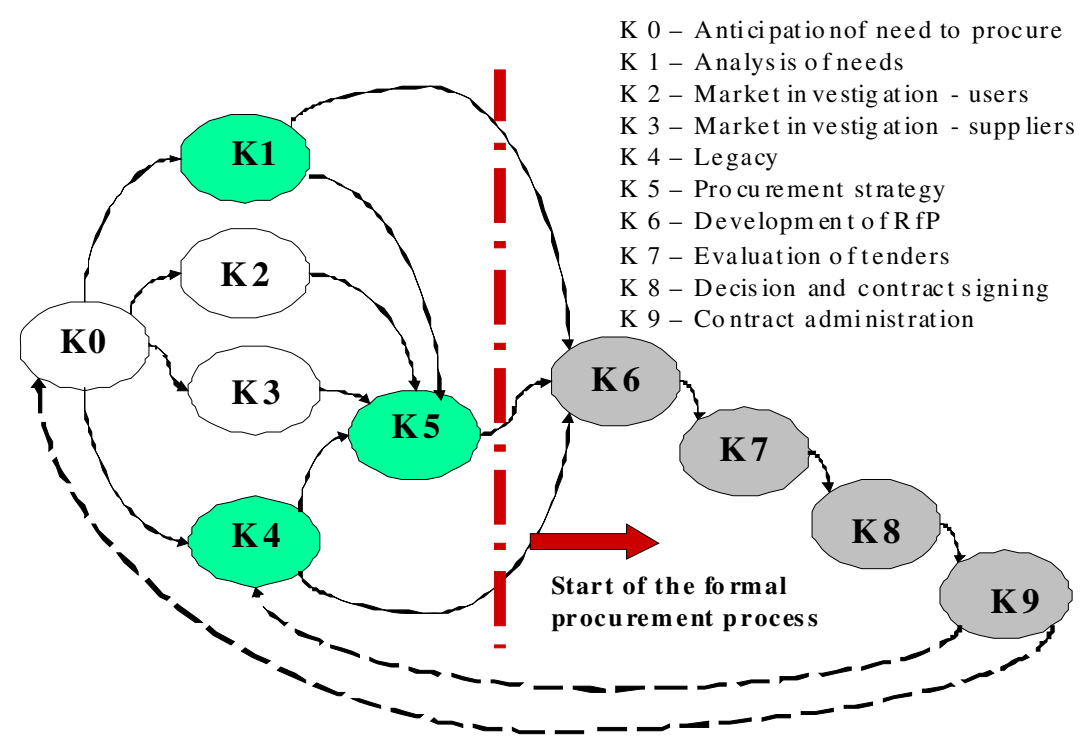

Fig. 1. Public procurement - the purchasing process of a public agency [21]

The organizational buying process has been analyzed and structured by several researchers, among them [35], [29], [36] and [19]. Their research findings constitute the base for structuring and analysing the public procurement process of telecommunications services in the KNUT-project [22].

The public agency's buying process shown in Figure 1 is composed of ten phases and some of them can be carried out in parallel. The parts K1, K4 and K5 were developed in the KNUT project and $\mathrm{K} 6, \mathrm{~K} 7, \mathrm{~K} 8$ and $\mathrm{K} 9$ are the parts already available on the market. 
K0 - Anticipation of need to start a procurement process. At this stage the organization, and especially its procurement department, observes the need of a new procurement (link with Figure 3). The absolutely most common reason to anticipate the need of the new procurement is the situation when the current contract is about to expire. If this happen close to the expiration date of the valid contract, it can be difficult to allocate enough time to carry out all necessary steps such as market investigations, analysis of needs, survey of legacy or choosing the procurement strategy.

\section{K1 - Collection and analysis of needs}

This is an internal activity in order to know what is needed in detail. Collection and analysis of needs often start with an analysis of the current situation and sometimes with a formulation of vision and strategy to achieve the vision. The vision can concentrate on "core" activities, improvement of the service level towards citizens and businesses, increased efficiency and reduction of costs.

\section{K2 - Market investigation - users}

This is an activity in order to find information about what others already have done in similar types of procurements. To meet other public agencies, private companies and/or users' associations in the own country or abroad and learn from their experiences from procurement of telecom services can be a very efficient way to develop RfPs and to avoid repeating errors committed by others. In contrast with private companies, there is no competition between public agencies, which gives possibilities to exchange experiences regarding suppliers, procurement process and internal difficulties. This input can be very valuable for the procuring agency in order to avoid problems or at least to be conscious of their existence.

\section{K3 - Market investigation - suppliers}

Public agencies are allowed to have contacts with manufacturers, operators and standardization organizations in the pre-study and market investigation phase. It is important to make use of this possibility in order to avoid unrealistic or costly requirements as well as to avoid missing important "in the pipeline" future services, solutions or functions.

\section{K4 - Collection of information regarding legacy}

This is an internal activity that investigates and collects information about already existing contracts and equipment within the organization. The most important parts of this investigation in case of telecommunications are legacies in form of ownership of properties, $\mathrm{PABX}^{3}$ s, terminal equipment, and routers, and own networks such as building wiring or municipal broadband network. Other important parts are currently valid contracts on fixed connections, telephony services, switched board operators services, call center services etc. All these aspects must be taken into account in the development of the RfP.

\footnotetext{
${ }^{3}$ PABX - Private Automatic Branch Exchange.
} 


\section{K5 - Choice of procurement strategy}

In this activity, the procuring organization investigates possible procurement scenarios and carries out the analysis of the consequences for each of these scenarios. The choice of the procurement scenario heavily depends on earlier undertaken investigations in $\mathrm{K} 1, \mathrm{~K} 2, \mathrm{~K} 3$ and $\mathrm{K} 4$.

In case of procurement of telecommunications, the KNUT project found three main scenarios:

1. Purchase of equipment,

2. Leasing of equipment

3. Service procurement (procurement of function)

Each of the main scenarios has several sub scenarios.

\section{K6 - Development of Request for Proposal (RfP)}

The development of the RfP is the central internal activity for public procurement. It includes structuring of mandatory and non-mandatory requirements, decision upon evaluation criteria, and often also contract proposal. Phases K1, K4 and K5 are input values for this activity. In the case of well carried out analysis of needs, legacy and choice of procurement strategy, the development of the RfP can be done automatically, i.e. electronically. With the development of the RfP starts the formal procurement process. The RfP cannot be changed after being published.

\section{K7 - Evaluation of tenders}

Tenders that do not comply with mandatory requirements are rejected and most of the evaluation will be concentrated on non-mandatory requirements and prices following the evaluation criteria. As a result one or several suppliers are chosen for decision taking.

\section{K8 - Decision taking and contract signing}

Decision taken by the procuring organization is valid only after giving during the stipulated time the possibility for the loosing tenderers to make a court appeal if they consider themselves being mistreated.

K9 - Ordering, invoicing, and follow-up - After the contract is signed and up and running, the delivery and invoicing period starts depending on the type of goods or services. In case of framework contracts from a designated agency that procures on behalf of other public agencies, it is necessary to have a call-off contract with each specific agency that is calling off from the framework contract. The delivery and invoicing is to the calling-off agency. In order to learn from the specific procurement, both buyer and supplier should measure customer satisfaction and results/profits. This is an important and valuable input for decision making for tendering in other procurements in the same area. 
The KNUT project aimed especially on the development of a model and a tool for the phases $\mathrm{K} 1, \mathrm{~K} 4$ and $\mathrm{K} 5$ since the information from these phases can directly be transferred to already existing electronic procurement tools for the development of the RfP. The KNUT project developed the methodology and a tool for purchasing telecommunications services. The results of the project were tested in a real life procurement of telecommunications services in Swedish local community Lindesberg.

The experiences from this procurement could be used for procurements of telecommunications services by other entities and/or as a model for development of similar applications for other complex procurements. Possibly the most important learnt lesson from this the project and the test is that carrying out of the phases ( $\mathrm{K} 0-\mathrm{K} 5)$ before the formal procurement phase starts are crucial in order to achieve the best results and it is also in these phases that the usage of Knowledge Management methods can of great help.

A Knowledge Management approach combined with electronic way to carry out procurement activities can play a great role in increasing the efficiency of the whole process [14].

\section{$4 \quad$ Research Method}

The research method we apply considers a whole cycle of life of knowledge related to procurement activity. This cycle includes understanding (existing elements and needs), modeling, choice of appropriate techniques and feedback integration. Amongst the various KM approaches those of bottom-up supervised by a top down [24] seems the most suited to study the knowledge flow of a procurement process. It consists in deep understanding of the procurement cycle of life from activity, involved actors and a related flow of knowledge points of view. The internal and external sources of knowledge are studied as well.

The $\mathrm{KADS}^{4}$ way of thinking [5] will guide this analysis in aim to:

- determine a goal,

- analyze the knowledge involved in the procurement process,

- indentify the contextual knowledge (all external knowledge that apply as legal, environmental and others, necessary for understanding of all procurement aspects and their connections.

- define the actions (tactics) leading to the achievement of a given goal.

A general KADS structure is presented in Figure 2.

\footnotetext{
${ }^{4}$ Knowledge Acquisition Design Systems - European project Esprit 2.
} 


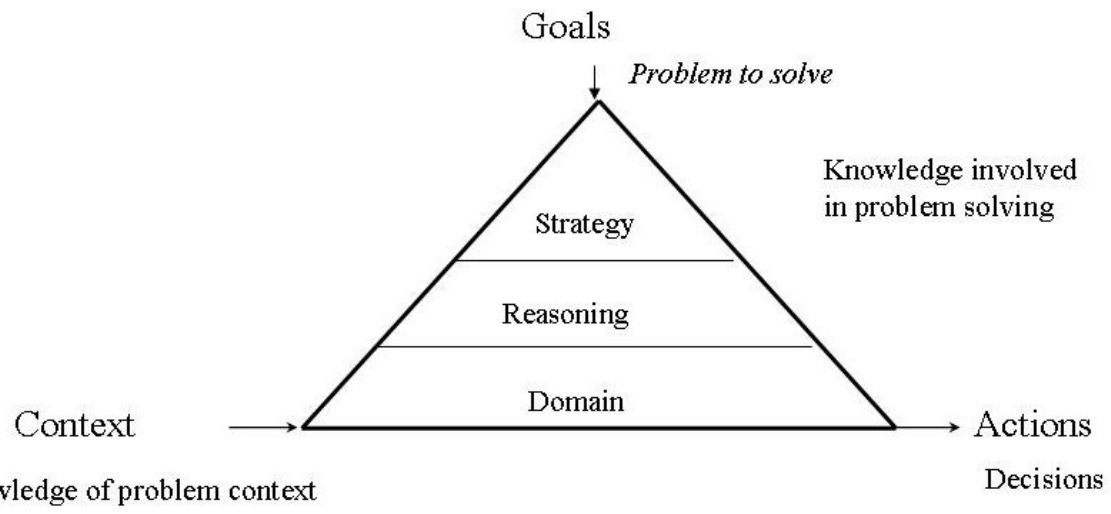

Knowledge of problem context

Fig. 2. Problem solving using knowledge

KADS, conceived for effective designing of knowledge-based systems [32], takes into account the contextual knowledge, which is, in many cases, essential in decision making process. Initially designed to assist knowledge engineers and experts in building a conceptual knowledge models and built upon principles of genericity, modularity and reusability, KADS is also a way of thinking and problem solving. Conceptual knowledge models are independent of implementation [28] and can also serve for others applications. The goals are "translated" into a strategy and/or graph. Each leaf of this graph corresponds to a reasoning model drafted for a specific purpose. It can be generalized and instantiated for other similar reasoning according to principles described by Clancey [8]. The domain layer contains static knowledge expressed by hierarchically organized concepts and relations between them. Ontology is an example of such a knowledge model.

In this context, the strategy of a studied organization is a part of contextual knowledge. It can influence the way of problem solving by chaining the actions, organization of actors and/or of information system (top-down). An important point is the strategy of addressing the right actors the organization wants to respond to tenders. The RfP must be crafted to attract targeted businesses. If they want to attract SMEs the application format should be simplified and comprehensive.

At this step we will get a clear vision of knowledge related to the procurement process and its nature. The next step is the understanding of the real needs of those involved in the procurement process. The needs engineering method [23], [24], [25] is particularly useful for discovering their unexpressed needs. It consists in observing the users activity and working with them on elaborating the requirements of a future system. During this step new functions or services useful for users can be suggested. While the majority of applications and service providers are satisfied with expressed needs, the unexpressed ones are the potential source of innovation. Such a way of working "transforms" the users to "co-creators" of a future application; this fact is vital for appropriation of a new solution by them. 
The Figure 3 presents the benefits of involving selected users into a coconstruction of the future application.

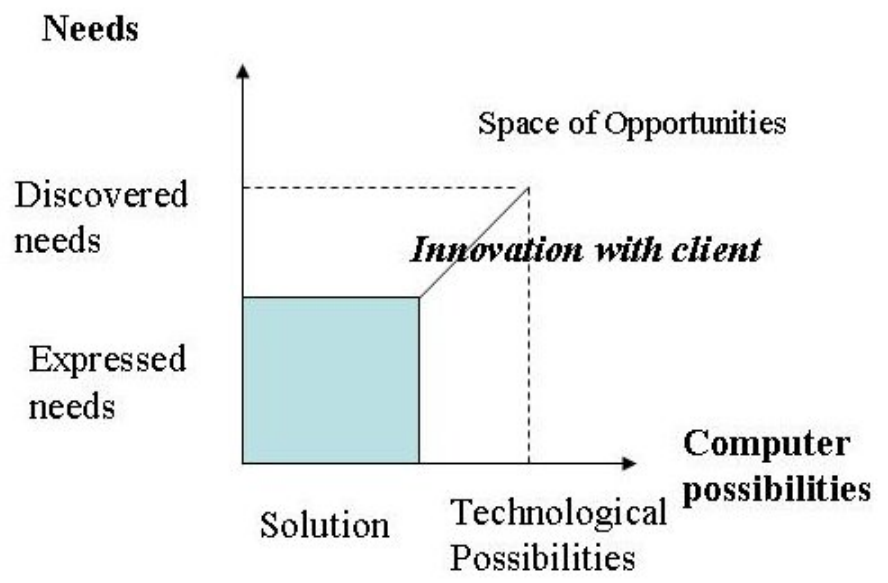

Fig. 3. Discovering of needs with future users

Traditional identification of needs and addressing them keeps participants in a small square; they have a little chance to innovate. Implication of clients allows both clients and service providers to reach the space of opportunities. It can lead to creation of new products and services.

Supervising by "top-down" means that we need to know the studied organization strategy to adapt our application to existing situation, but in the same time the feedback from the elaborating and use of the application can influence the strategy. In some cases an "innovation process management assessment" [25] may be introduced to argument the necessary adaptation and to provide a tool for systematic innovation management simultaneously. In reality many organizations and companies that consider themselves innovative are not managing the "knowledge innovation" process "from idea to values".

The analysis of a knowledge flow is fundamental for suited knowledge organization supporting the procurement activity in connection with the others organizational processes.

The KNUT project results are our starting point for this study.

\section{The Role of Knowledge Management in Electronic Public Procurement}

While there are many publications on e-Procurement and Knowledge Management we found only few connecting the both fields. The main effort is made on recording documents related to request for proposals, and past tenders into an organizational 
memory in aim to have quick access and a possibility to reuse existing knowledge [10], [8].

The MNEMOS project was, on our knowledge, the first that applied a Knowledge Management approach to a procurement process. Matra Marconi Space (MMS) activities were multidisciplinary combing knowledge about physics, electronics, satellites, information processing and other related fields. To assist MMS commercial engineers in relevant and quick answering the tenders by providing them an easy access to company knowledge was the main motivation for introducing KM through organizational memory [26].

Latter they added to the knowledge flow a skill management and decision support systems [27]. This project is a good example of bottom-up and incremental KM approach.

At present two main categories of approaches can be found - first emphasizes on management methods and organizational change and second focus on ICT, knowledge modelling and processing.

The first category discusses the importance of including procurement into an organizational strategy [18], managing knowledge and skills relative to the procurement process [12] and redesigning e-procurement as a new operating practice [14].

The second category focuses on management of the procurement process using traditional information technology and knowledge techniques as well. De Nicola [10] work is about knowledge modelling and processing and in particular they propose knowledge models such as ontology, while Vlahovic [33] research focus is on knowledge storing and processing.

De Nicola [10] describes also the interoperability between two different software applications and documents. Ontology is considered as a "common language" as well for applications as for involved various actors. A common language is one of the pillars of effective Knowledge Management.

Vlahovic [33] presents a system composed of database for storing information about calls for tenders and related documents. It is also used to track status of the call, either its expiry or cancelation if one is published. The information extraction techniques allow to access and retrieve information and accompanying documentation.

His knowledge base contains past tenders and feedback information supplied by client users. The analogy engine (case-based reasoning) provides information about preparing optimized proposals, estimating other characteristics of the tender and calculating possible expectations in terms of contract negotiation, ordering and payment. All of this information is made available to potential contractors through the client application to enhance their decision making procedures.

Quite whole KM cycle of life including identification, recording using models and processing is covered here:

Knowledge Management (KM) has been introduced as a new management method in the late 1980s [11], [31], [2] and a decade latter via ICT (Information and Communication Technology), mainly without taking into account the artificial intelligence approaches, techniques and experiences in building various knowledge-based systems. While one of the objectives of Artificial Intelligence (AI) has always been knowledge modelling and processing, the KM have been introduced to this field in early 1990s 
via Corporate Knowledge [7] and Organizational Memory concepts [9] Corporate Knowledge goal is to build an optimized knowledge flow for a given organization using conceptual knowledge modelling (Knowledge Models) and storage (Knowledge Repository), intelligent access to knowledge (Knowledge Navigator) using hypertext and semantic navigation in the knowledge repository and make it available for decision making (Corporate Decision) - [24].

The importance of external contributors (stakeholders), including clients for the organizational strategy has been better understood in the same period [2], [25].

By consequence, the definition of Knowledge Management we propose is following:

The organized and optimized system of initiatives, methods and tools designed to create an optimal flow of knowledge within and throughout an extended enterprise to ensure stakeholders success (Amidon, Mercier-Laurent, 1997).

According to this definition, AI plays an essential role in the optimizing of the knowledge flow and processing the knowledge elements influencing the success of all participants. AI techniques are effective for capitalization of knowledge elements to reuse, for collecting of "best" practices, feedback processing and decision making. AI helps in providing an intelligent guiding (tasks and reasoning models) to involved persons in accomplishing of the whole procurement process.

Information and Communication Technology will facilitate sharing of relevant elements amongst participants.

In the case of public procurement process, the related internal knowledge contains the elements such as needs, potential suppliers, technical knowledge, available technology, past projects and experience. In the majority of cases this knowledge is in the heads, sometimes it is shared by email. The elements of external knowledge are legal, political, environmental, economic and technological nature. This knowledge is spread over the web and documents.

The electronic procurement allow reducing paper, but also introducing the new way of thinking relative to usage of this media and instantaneous access to world base of information. Instead of reproducing the paper mechanism, a given organization can innovate in the way of preparing, diffusing and processing the proposals as well as in the way of capturing knowledge, opportunities in real time and for decision taking.

\subsection{Knowledge Flow for e-Procurement}

Each step of the process presented in Figure 1 needs internal and external knowledge to act and produces knowledge as well. Some elements of knowledge are shared by several steps. These steps organization could be considered as initial flow of knowledge. The process of procurement exchanges knowledge with other organizational processes and applications, such as services provided to citizens and enterprises, for example call for projects, electronic tax collection, healthcare, car registration and practically all internal processes. 
A preliminary analysis of a knowledge flow related to e-procurement process is shown in Figure 4. The involved actors are organizations, procurement department, partners, suppliers, clients, citizens and businesses. Knowing them is vital for successful managing of procurement. All produce, have and use knowledge.

This flow is generic and works for purchase of equipment, leasing of equipment and service procurement as well.

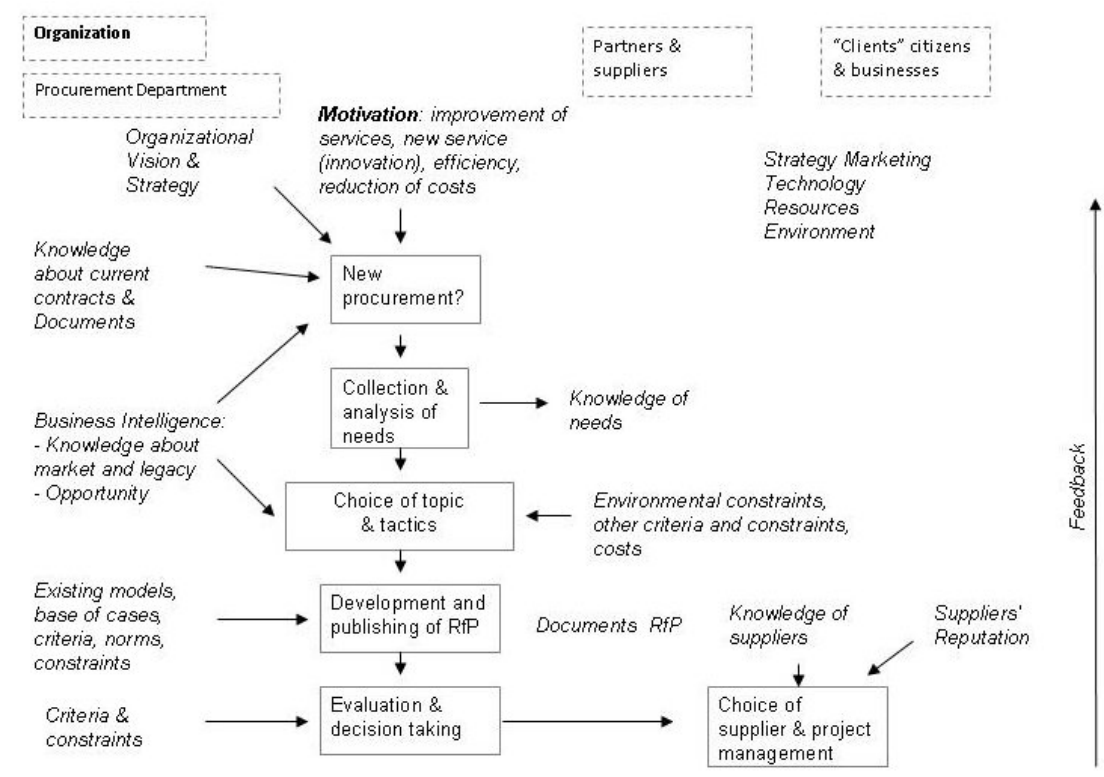

Fig. 4. Knowledge flow for procurement process

The anticipation and definition of needs involve the elements like knowledge on existing contracts and constraints such as end of current contracts, results, skills and other resources, legal and environmental constraints. It depends on organizational vision and strategy. Motivations of actors play an important role in the innovation process - they may detect a need for a new service or improvement of existing by adding for example the environmental aspects. Motivation by only reduction of costs may influence a new more effective organization or...relocation of services and lost of local jobs.

At this stage and all along the process the participants need the access to existing knowledge and support in finding the relevant information and opportunity watch (Business Intelligence). The AI techniques of knowledge discovery such as text mining and semantic search can be helpful. Business Intelligence (BI) is also useful in continuous discovering of new providers and services, laws, opportunities, practices and technology.

As mentioned before a collection and analysis of needs should be improved by adding "needs discovery" aspects [23]. It includes the involvement of selected users 
into the early stage of procurement process. In function of a type of organization it may include the knowledge about citizens businesses and their expectations.

Market investigation involves knowledge on similar types of procurement (known cases), feedback from experiences, users [34] and suppliers. Availability of all this knowledge can enhance the effectiveness of the whole process.

The information on legacy, environmental and other constraints to be considered can be collected by all participants and semantic search. However, for better efficiency the knowledge exchange should be organized to avoid spamming and waste of time.

The choice of knowledge-based procurement strategy and tactics will be based on knowledge of benefits related to the various scenarios:

- Purchase of equipment,

- Leasing of equipment

- Service procurement (procurement of function)

Corporate Social Responsibility (CSR) and norms related to environmental impact (ISO 26000 and 14001) encourage choosing rather the last scenario, if possible. Leasing of equipment and services of function procurement become more popular because of the environmental constraints. Some economists advice to focus more on leasing and service procurement rather than on purchase [16], [6].

The scenarios should also take into consideration knowledge about relevant business models in order to choose one or more that best suits a given case.

At the stage of evaluation the benefits and impact of a given choice can be simulated to help decision taking.

A continuous feedback from experience, which is also an attitude of knowledge cultivator, will allow improving the both e-procurement processing and knowledge management. A system of practice collection and processing, using for ex case-based reasoning (analogy) could be an added value. The opening to external knowledge, such as experience with suppliers and tools is vital.

The tasks chaining represented in Figure 1 may be considered as a generic reasoning model for e procurement process and tested in various fields.

The described knowledge flow is the first step of Knowledge Management approach. It should be validated by applying to KNUT project and tested on a real case.

\subsection{Knowledge Management and KNUT Model/Tool}

After understanding of the procurement and e-procurement processes specificities and getting a clear representation of involved actors and flow of knowledge, the next step will deal with knowledge modelling and a choice of appropriate tools.

One of the important prerequisites for the best usage of the KNUT model is the construction or adaptation from existing generic knowledge models for collection of information from already carried out procurements. The RfPs, procurement processes and contracts could be then compared as well as all comments taken automatically into account. 
At this stage we will study existing ontologies. KNUT conceptual knowledge model can be built incrementally or adapted from existing. The use of knowledge modelling techniques will facilitate more effective RfP construction; a new RfP can be quickly composed with existing modules, as Lego ${ }^{\mathrm{TM}}$ toys. The phase of proposals evaluation may follow an appropriate reasoning model and use a decision support system and constraint propagation engine if apply.

The feedback form testing of KNUT model combined with Knowledge Management approaches and techniques will be integrated to improve the whole cycle of life.

With the collective, aggregated knowledge about procurements of specific goods or services (in case of KNUT model/tool, it deals with telecommunications services) $\mathrm{KM}$ techniques can not only speed up the process of development of a RfP but also to analyze and then improve both the model/tool and next procurements that use the model. It can influence more accurate choices.

\section{Conclusions and Perspectives}

Public procurement could be a first step in introducing a holistic knowledge management approach in organizations that are not yet practicing it. The described case is just a beginning of a larger project which could be followed by a $\mathrm{PhD}$ student using KNUT model and working on a real case in aim to study a genericity of knowledge models and reasoning related to electronic public procurement. A tool for assistance for procurement cycle of life will be prototyped and tested.

Knowledge Management approach will certainly increase the efficiency of the procurement process by organizing and optimizing the related knowledge collection, modelling and processing, including access and sharing. The reuse of existing knowledge components and experiences, as well as the quick access to relevant information will help more effective development of RfP. Knowledge-based decision support system may assist in the process of evaluation and in the choice of the best supplier.

The procurement process is just one element of organizational flow of knowledge, which has a potential of the integration of other processes into the whole flow of knowledge. It may impulse the systematic management of the innovation process. It can also influence the organizational strategy.

The AI approaches and techniques can bring a significant help in knowledge gathering, modelling, reusing as well as in discovering knowledge from data, text and image when apply.

To attract the SMEs, the whole procedure should be simplified to focus on essential in aim to encourage the SMEs to apply for tenders. A SME can not spend a month answering if it is not sure to gain the contract. Testing the elaborated model on some SMEs may be of interest in this case.

The experience in introducing the Corporate Social Responsibility in organizations may bring interesting feedback to e-procurement policies and process. 


\section{References}

1. Ahlström, M.: Offset Management for Large Systems - A Multibusiness Marketing Activity. Linköping University, Studies in Management and Economics (2000)

2. Amidon, D.: The Innovation Strategy for the Knowledge Economics. Butterworth Heinemann (1997) ISBN 0750698411

3. Axelsson, B., Håkansson, H.: Industrial Procurement. LiberFörlag (1984)

4. Bonnacorsi, A., Pammolli, F., Tani, S.: The changing boundaries of system companies. International Business Review 5(1) (1996)

5. Schreiber, G., Wielinga, B., Breuker, J.: KADS, A Principled Approach to KnowledgeBased System Development. Academic Press (1993)

6. Buclet, N.: Concevoir une nouvelle relation à la consommation: l'Economie de fonctionnalité. In: Annales des Mines, pp. 57-66 (Juillet 2005)

7. CEDIAG Corporate Knowledge, internal Bull document (confidential), described in [23] (1991)

8. Clancey, W.J.: Heuristic classification. Artificial Intelligence 27 (1985)

9. Conklin, E.J., Star, S.L.: Organizational Memory. In: Proceedings of the Second European Conference on Computer-Supported Cooperative Work, ECSCW 1991, pp. 189-190 (1991)

10. De Nicola, A., Missikoff, M., Misceo, F.: A Core Business Ontology for eProcurement: a First Proposal. In: The Proceedings of itAIS 2005, 2nd Conference of the Italian Chapter of AIS (2005)

11. Drucker, P.: The New Society of Organizations. Harvard Business Review (SeptemberOctober 1992)

12. Egbu, C., Vines, M.P., Tookey, J.: The role of knowledge management in e-procurement initiatives for construction organizations. In: Greenwood, D.J. (ed.) Proceedings 19th Annual ARCOM Conference, September 3-5, vol. 2, pp. 661-669. Association of Researchers in Construction Management, Brighton (2003)

13. European Commission. Directive 2004/18/EC of the European Parliament and of the Council of 31 March 2004 on the coordination of procedures for the award of public works contracts, public supply contracts and public service contracts (2004)

14. Federici, T., Resca, A.: Managing E-Procurement in Public Healthcare: A Knowledge Management Perspective. International Journal of Healthcare Delivery Reform Initiatives (IJHDRI) 1(1) (2009)

15. Gelderman, C.J., Ghijsen, P.W.T., Brugman, M.J.: Public procurement and EU tendering directives - explaining non-compliance. International Journal of Public Sector Management 19(7), 702-714 (2006)

16. Giarini, O., Stahel, W.R.: The Limits to Certainty, Facing risks in the new service economy-International Studies in the Service Economy. Kluwer, The Netherlands (1989)

17. Goldkuhl, G., Axelsson, K.: E-services in public administration. International Journal of Public Information Systems 3, 113-116 (2007)

18. Knudsen, D.: Aligning corporate strategy, procurement strategy and e-procurement tools. International Journal of Physical Distribution \& Logistics Management 33(8), 720-734 (2003)

19. Kotler, P.: - Marketing Management Analysis, Planning, Implementation, and Control, 9th edn. Prentice Hall, USA (1997)

20. Leukel, J., Maniatopoulos, G.: A comparative analysis of product classification in public vs. private e-procurement. The Electronic Journal of e-Government 3(4), 201-212 (2005) 
21. Lindskog, H.: Process of Public Procurement of Telecom Services, The Buyer's Perspective. In: Proceedings of the 7th ISOneWorld Conference, Las Vegas (2008)

22. Lindskog, H.: KNUT Elektronisk offentlig upphandling av telekommunkationstjänster, slurapport, Vinnova (2010)

23. Mercier-Laurent, E.: From Data Programming to Intelligent Knowledge Processors: How Computers Can Improve the Global KM Flow. Cutter IT Journal 17(12), 33-39 (2004)

24. Mercier-Laurent, E.: Rôle de l'ordinateur dans le processus global de l'innovation à partir de connaissances, Mémoire d'Habilitation à Diriger les Recherches en Informatique, Université Lyon 3 (2007)

25. Mercier-Laurent, E.: Innovation Ecosystems. Willey-ISTE (2011) ISBN: 978-1-84821325-8

26. MNEMOS. Comment Matra Marconi Space batît sa mémoire technique, IL'Usine Nouvelle ${ }^{\circ} 2543$ (Avril 04, 1996), http: / / www. usinenouvelle.com/

article/gestion-de-projetcomment-matra-marconi-space-

batit-sa-memoire-techniquele-constructeur-de-satellites-

construit-metier-par-metier-un-systeme-de-capitalisation-

des-connaissances-reutilisables-obj.N78526

27. MNEMOS (1998), http: / /www. eurekanetwork.org/project/-/id/1093

28. Newell, A.: The knowledge level. Artificial Intelligence 18 (1982)

29. Robinson, P.J., Faris, C.W., Wind, Y.: Industrial Buying and Creative Marketing. Allyn and Bacon Inc., Boston (1967)

30. Roodhooft, F., Van den Abbeele, A.: Public procurement of consulting services: Evidence and comparison with private companies. International Journal of Public Sector Management 19(5), 490-512 (2006)

31. Savage, C.: 5th Generation Management: Integrating Enterprises through Human Networking. The Digital Press, Bedford (1990)

32. Dolenc, N., Libralesso, J.-M., Thirion, C., Gobrecht, A., Lesaffre, F.-M., Hellelsen, M., Lalhier, M., Lenuet, D., Steller, J.-M.: The SACHEM Project: Blast Furnace Operating Support System; Ambition and Stakes, Development and First Results. In: 3rd European Ironmaking Congress, Gent, Belgium, September 16-18 (1996)

33. Vlahović, N.: Public Knowledge Base System for Public eProcurement: A Conceptual Model. In: The Proceedings of the 5th WSEAS International Conference on Management, Marketing and Finances (MMF 2011), pp. 251-256. WSEAS Press, Athens (2011) ISBN: 978-960-474-287-5

34. von Hippel, E.: Learning from Lead Users. In: Buzzell, R.D. (ed.) Marketing in an Electronic Age, pp. 308-317. Harvard Business School Press, Boston (1985)

35. Webster, F.E.: Modeling the Industrial Buying Proces. Journal of Marketing Research 2, 370-376 (1965)

36. Wind, Y., Thomas, J.R.: Conceptual and Methodological Issue in Organizational Buying Behaviour. European Journal of Marketing 14, 239-286 (1980)

37. http://ec.europa.eu/idabc

38. http://europa.eu/publicprocurement

39. http://www.peppol.eu

40. http://cordis.europa.eu/fp7/ict/pcp/key_en.html

41. http://ec.europa.eu/internal_market/publications/docs/ public-procurement_en.pdf 